\title{
Evaluation of antioxidant, diuretic, and wound healing effect of Tulkarm honey and its effect on kidney function in rats
}

\author{
Hamada Imtara ${ }^{1}$, Noori Al-Waili ${ }^{2}$, Meryem Bakour ${ }^{1}$, Wail Al-Waili² and Badiaa Lyoussi ${ }^{1}$ \\ 1. Laboratory of Physiology, Pharmacology and Environmental Health, Faculty of Sciences, Dhar El Mehraz, BP 1796 \\ Atlas, University Sidi Mohamed Ben Abdallah, Fez 30 000, Morocco; 2. Department of Nephrology and Hypertension, NY \\ Medical Care for Nephrology, New York, USA. \\ Corresponding author: Noori Al-Waili, e-mail: noori786@yahoo.com \\ Co-authors: HI: hamada.tarayrah@gmail.com, MB: mersvi08@hotmail.fr, \\ WA: drnoori6@yahoo.com, BL: lyoussi@gmail.com \\ Received: 07-06-2018, Accepted: 21-09-2018, Published online: 25-10-2018
}

doi: 10.14202/vetworld.2018.1491-1499 How to cite this article: Imtara H, Al-Waili N, Bakour M, Al-Waili W, Lyoussi B (2018) Evaluation of antioxidant, diuretic, and wound healing effect of Tulkarm honey and its effect on kidney function in rats, Veterinary World, 11(10): 1491-1499.

\begin{abstract}
Aim: The composition and activity of honey depend on its floral origin. Honey collected from Tulkarm was evaluated for physicochemical property and antioxidant content as well as a diuretic and wound healing activity. Its effect on kidney function was evaluated and compared with furosemide.

Materials and Methods: Honey was collected in Tulkarm, Palestine, and its phenol, flavones, and flavonol content were assessed. The antioxidant activity was determined with the use of colorimetric assays, 1,1-diphenyl-2-picrylhydrazyl, ferric reducing antioxidant power, and 2,2-azino-bis(3-ethylbenzothiazoline-6-sulfonic acid). Two sets of experiments were conducted. First experiment: 18 rats were used for the evaluation of diuretic activity of honey. The rats received either honey or furosemide. Renal function test, uric acid, and serum and urine electrolytes assay were performed. Second experiment: 18 male mice were used to evaluate the wound healing property of honey. Wounds were created on mice skin and treated daily with honey or Madecassol. Measurements of wounds were performed over a period of 12 days.

Results: The physical and chemical parameters of Tulkarm honey are within the limits of the European legislation and fulfilling the criteria described in the standard codex for honey. It contains antioxidant compounds and shows antioxidant activity. Oral honey increased creatinine clearance and urine volume, sodium, and chloride without causing hypokalemia or affecting blood urea, uric acid, or serum creatinine level. The diuretic activity of furosemide was associated with hypokalemia. Topical honey application enhanced wound closure when compared with the Madecassol application.
\end{abstract}

Conclusion: The study is the first to report that honey collected from Tulkarm has a considerable diuretic effect without affecting serum electrolytes or kidney function test and exhibits strong antioxidant activity and wound healing property.

Keywords: furosemide, honey, kidney, Madecassol, wounds.

\section{Introduction}

Data have shown that honey has antibacterial, antiviral, antiparasitic, antimutagenic, anti-inflammatory, anticancer, and antioxidant activities, and it has potential in the improvement of wounds, ulcers, diabetes, hypertension, and cardiovascular disease [1-10]. Honey has been mentioned in Holy books, the Talmud, both the old and new testaments of the Bible, and the Holy Quran as a healer of diseases. In the Surat Al-Nahel (The Bee) it says: And your LORD taught the bee to build its cells in mountains, on tree and in men's habitations, then to eat of all the fruits of the earth and find with skill the spacious paths of its LORD, their issues from within their bellies, a drink of varying colors, wherein is

Copyright: Imtara, et al. Open Access. This article is distributed under the terms of the Creative Commons Attribution 4.0 International License (http://creativecommons.org/licenses/by/4.0/), which permits unrestricted use, distribution, and reproduction in any medium, provided you give appropriate credit to the original author(s) and the source, provide a link to the Creative Commons license, and indicate if changes were made. The Creative Commons Public Domain Dedication waiver (http://creativecommons.org/ publicdomain/zero/1.0/) applies to the data made available in this article, unless otherwise stated. healing for men, verily in this is a sign for those who give thought.

Studies have reported the beneficial effect of honey in kidney function and kidney pathology, particularly in diabetes. It has been found that in normal individual's oral honey collected in the United Arab Emirates increases urinary nitrite excretion, free water clearance, filtered sodium, and creatinine clearance. Furthermore, honey decreases urinary excretion of prostaglandins (PG) F2 alpha, thromboxane B2, and PG E2. On the contrary, artificial honey reduces urinary nitrite and raises urinary PG concentration [7]. Furthermore, carob honey collected in Morocco increases urine output and creatinine clearance during the acute or chronic mode of administration [8]. Interestingly, honey ingestion did not cause hypokalemia in spite of increased urine potassium and urine volume. In kidney diseases, Moroccan carob honey has a protective effect against lead-induced toxicity in rats; it ameliorated the elevation of serum creatinine and blood urea nitrogen induced by lead [9]. In addition, it was demonstrated that honey collected in the United Arab Emirates can protect liver and kidney 
during acute blood loss, food restriction, and after carbon tetrachloride intoxication [10-14]. Other studies found that honey from different regions showed a protective effect in cisplatin, carbon tetrachloride, and cyclophosphamide-induced kidney toxicity [15-17]. Honey treatment improved the kidney function, increased antioxidant enzymes, and decreased lipid peroxide levels and improved the morphology of the kidney cells of the melamine-fed rats [18]. Pretreatment with Sidr honey and silymarin before the administration of $\mathrm{CCl} 4$ significantly prevented the increase of the serum levels of liver enzyme and reduced oxidative stress. Sidr honey has a significant lipid-lowering effect and it protected liver and kidney lesions [17]. In diabetic rats, administration of honey reduced mesangial matrix expansion and thickening of glomerular basement membrane [19].

Honey bees (Apis mellifera) collected honey from different plants, and the composition of honey depends on the type of plant, climate, and environmental conditions. Regarding the complementary medicine use in certain areas of Palestine, it was reported that $72.8 \%$ of participants in the northern part of Palestine have used at least one type of complementary medicine. It was concluded that alternative medicine utilization in Palestine is very common which includes honey [20]. However, few studies have been published so far regarding the quality and functional properties of honey collected in Palestine. One of these studies showed that ingestion of Palestinian honey induces spermatogenesis in rats by increasing epididymal sperm count, increases the relative weight of the epididymis and lactate dehydrogenase activity, and reduces sorbitol dehydrogenase activity [21]. Furthermore, the volatile compounds as markers in Palestinian honey have been studied [22,23].

The objectives of the present study included evaluation of the quality of honey through the determination of physical, chemical, and antioxidant property, the diuretic effect of honey compared to furosemide, the effect of honey on kidney function test, and the wound healing effect of honey compared to Madecassol. This is the first study to explore these variables in Tulkarm honey collected in Palestine. Tulkarem is a coastal city famous by citrus and avocado trees.

\section{Materials and Methods}

\section{Ethical approval}

The care and handling of rats and mice were in accordance with internationally recognized standards guidelines for the use of animals. The protocol was approved by the Institutional Committee on Animal Care following the French Technical Specifications for the Production, Care and Use of the Laboratory Animals, University Sidi Mohamed Ben Abdellah, Faculty of science, Dhar Mehrez, Fez, Morocco.

\section{Physicochemical analysis}

Honey sample (Multifloral honey) was collected from the city of Tulkarm, Palestine. Analysis of sample was carried out in triplicate for each test to determine the physicochemical properties (moisture content, total ash content, electrical conductivity, $\mathrm{pH}$, free acidity, lactone acidity, proline, honey color, and melanoidin content). The measurements were achieved according to the International Honey Commission (IHC) [24]. The color was measured according to the method described earlier [25]. The degree of browning measured through the absorbance of samples between 420 and $450 \mathrm{~nm}$ is used to assess the extent to which the Maillard reaction occurs in foods, constituting one way to estimate the late-stage of the Maillard reaction products: The melanoidins [25].

\section{Analysis of antioxidant activity}

The antioxidant activity of honey was determined by different methods such as total antioxidant capacity, the radical scavenging activity of the honey solution toward 1,1-diphenyl-2-picryl hydrazyl (DPPH) free radical and 2, 2-azino-bis 3-ethylbenzothiazoline-6-sulfonic acid (ABTS*+), and ferric reducing antioxidant power [26-30]. All the assays were carried out in triplicate, and average values were considered. Several concentrations of samples were made, and the percentage inhibition and inhibitory concentration $\left(\mathrm{IC}_{50}\right)$ (concentration of sample able to scavenge 50\% of ABTS ${ }^{*+}$ or DPPH radicals) were determined.

\section{Analysis of phenol, flavones, and flavonol}

The total phenolic content was determined by the use of the Folin-Ciocalteu assay and total phenol content was expressed as $\mathrm{mg}$ gallic acid equivalents (GAEs)/100 g [26]. The total flavones and flavonol content were determined, and the results were expressed as $\mathrm{mg}$ quercetin equivalents (QEs)/100 g [31]. The antioxidant activities of honey samples were determined by the phosphomolybdenum method, and they were expressed relative to ascorbic acid (mg AAE/100 g) [32].

\section{Experimental animals}

Eighteen Wistar rats weighing between 200 and $240 \mathrm{~g}$ were used for the evaluation of diuretic activity and 18 male mice weighing between 28 and $35 \mathrm{~g}$ were used to observe the wound healing effect. The animals were obtained from the animal house breeding center, Faculty of Sciences, Dhar Al-Mahraz, Fez, and were housed under normal environmental conditions $\left(25 \pm 1{ }^{\circ} \mathrm{C} 55 \pm 5 \%\right.$ humidity and $12 \mathrm{~h} / 12 \mathrm{~h}$ cycle light/dark). The animals were allowed free access to tap water and standard laboratory food.

\section{Reference drug}

Furosemide (Lasilix, Pharma 5, Morocco) was used as a reference drug. Madecassol cream (Bayer laboratory, France) was used as reference drug for wound healing. One gram of Madecassol, 1\% cream, contains $10 \mathrm{mg}$ Centella asiatica; (reconstituted titrated dry extract containing asiaticoside; madecassic and asiatic acids)

\section{Biochemical methods}

Blood samples were collected in capillary tubes containing ethylenediaminetetraacetic acid by 
retro-orbital puncture under light diethyl ether anesthesia. After centrifugation at $3500 \mathrm{RPM}$ for $10 \mathrm{~min}$, the plasma was separated and kept at $-20^{\circ} \mathrm{C}$ until analysis. The levels of the blood and urine sodium, chloride and potassium were measured with the use of a spectrophotometer. Kidney function test was performed by estimation of serum creatinine, uric acid, and blood urea nitrogen. Osmolar clearance was determined from plasma osmolality, urinary osmolarity, and urine flow according to the following formula: Osmolar clearance=urinary osmolarity $\times$ urine flow/plasma osmolality. Free water clearance was determined from plasma osmolality, urinary osmolarity, and urine flow according to the following formula: Free water clearance $=$ urine volume $(\mathrm{ml} / \mathrm{min}) \times(1$-urine osmolarity/ plasma osmolarity). $\mathrm{T}_{\mathrm{CH} 2 \mathrm{O}}$ (free water reabsorption) was assessed by $\mathrm{C}_{\mathrm{H} 2 \mathrm{O}}$ according to the following formula; $\mathrm{T}_{\mathrm{CH} 2 \mathrm{O}}=-\left(\mathrm{C}_{\mathrm{H} 2 \mathrm{O}}\right)$.

\section{Assessment of diuretic activity}

Each animal was placed in an individual metabolic cage for a period of 3 days to adapt to the new conditions before the experiment. The rats were randomly divided into three groups, sex animals each: Group 1 received oral administration of distilled water at a dose of $10 \mathrm{ml} / \mathrm{kg} . b . w t$ and served as the control group, Group 2 was treated with an oral dose of $10 \mathrm{mg} / \mathrm{kg}$.b.wt of furosemide, and Group 3 received oral administration of $100 \mathrm{mg} / \mathrm{kg} . b . w t$ of the honey. After administration of the interventions, urine samples were collected and measured at 1, 2, 4, 6, and $24 \mathrm{~h}$ after the first dose of each intervention. Then after, daily oral doses were administered to three groups of rats for 11 days, and for each rat, $24 \mathrm{~h}$ urine was collected daily and its volume was measured. Urinary sodium, chloride, and potassium concentrations were measured in the urine specimens on day 11. Serum sodium, potassium, chloride, uric acid, and creatinine levels, blood urea nitrogen, and urinary creatinine excretion were measured on day 11 . Other variables, including plasma and urine osmolarity and free water clearance, were also measured on day 11.

\section{Effect of honey on wound healing}

The mice were anesthetized through intraperitoneal injection of pentobarbital sodium $(0.05 \mathrm{mg} / \mathrm{g}$ weight), and their dorsal hair was shaved off. A circular full-thickness skin wound $(7.4 \mathrm{~mm}$ in diameter), which included the panniculus carnosus muscle, was performed on the skin of each mouse. The animals were divided into three group's six mice each: Group 1 (Control) no treatment; Group 2 (Madecassol group) received a daily application of Madecassol ointment applied directly to the skin; and Group 3 (the honey group) received a daily application of honey applied directly to the wounds. The wound healing was observed on days $1,3,7$, and 12 . The edges of the wounds were traced on polypropylene sheets, and photographs of the wounds were taken every day. The traces on the polypropylene sheets were then captured with a scanner and transferred to the computer using the image processing software (Picture manager) to improve contrast. The area of each wound was calculated using the image analysis software Adobe Illustrator CS5 NA. The wound was treated daily by applying Madecassol. In honey group, the wound was treated daily by applying $0.1 \mathrm{ml}$ of the honey $(5 \mathrm{~g}$ of honey $+1 \mathrm{ml}$ of distilled water).

\section{Statistical analysis}

The results were expressed as mean values \pm standard error of the mean. Statistical analysis of the data was performed with one-way analysis of variance (ANOVA) followed by Tukey's multiple comparison test (ANOVA followed by Tukey's test) (GraphPad Prism, version 6). Significant differences were indicated by $\mathrm{p}<0.05$.

\section{Results}

The physicochemical parameters and antioxidant content

The physicochemical parameters of honey studied revealed that the $\mathrm{pH}$ is $4.70 \pm 0.01$, free acidity is $42.17 \pm 2.08 \mathrm{mEq} / \mathrm{kg}$, lactone acidity is $7.73 \pm 1.17 \mathrm{mEq} / \mathrm{kg}$, total acidity is $49.89 \pm 1.24 \mathrm{mEq} / \mathrm{kg}$, the percentage of moisture is $17.73 \pm 0.115 \%$, electric conductivity is $1153.33 \pm 4.51 \mu \mathrm{S} / \mathrm{cm}$, ash is $0.508 \%$, color is $0.18 \pm 0.03$, melanoidin is $0.44 \pm 0.02$, and proline is $448.81 \pm 5.06 \mathrm{mg} / \mathrm{kg}$. The classification of the honey depends on the value of Pfund scale $(78.77 \pm 5.31 \mathrm{~mm})$ indicating that the honey is light amber.

The data showed that the level of polyphenol is $78.79 \pm 1.43 \mathrm{mg}$ AGE $/ \mathrm{kg}$, flavones and flavonols are $4.47 \pm 0.23 \mathrm{mg} \mathrm{QE} / \mathrm{kg}$, and total antioxidant capacity is $70.76 \pm 1.89 \mathrm{mg} \mathrm{AAE} / \mathrm{g}$. The antioxidant activities results showed that the $\mathrm{IC}_{50}$ is $17.14 \pm 1.40 \mathrm{mg} / \mathrm{ml}$ for DPPH assay, $3.16 \pm 0.70 \mathrm{mg} / \mathrm{ml}$ for ABTS*+ assay, and $1.32 \pm 0.03 \mathrm{mg} / \mathrm{ml}$ for ferric reducing antioxidant power.

\section{Effect of honey on urine and plasma electrolytes and urine volume and osmolarity}

Treatment with a single dose of Tulkarm honey increased urine output, which became significantly higher than the water at $4 \mathrm{~h}$ after the administration (Table-1). The urine output was increased significantly

Table-1: Urine volume during 11 days with daily oral administration of the interventions.

\begin{tabular}{lccc}
\hline Days & \multicolumn{3}{c}{ Urine volume (ml/24 h) } \\
\cline { 2 - 4 } & Water & Honey & Furosemide \\
\hline 1 & $5.67 \pm 0.34$ & $6.50 \pm 0.29^{+}$ & $7.00 \pm 0.58^{+}$ \\
2 & $6.00 \pm 0.58$ & $8.40 \pm 0.06^{+\#}$ & $8.17 \pm 0.09^{+}$ \\
3 & $5.74 \pm 0.21$ & $7.53 \pm 1.07^{+\#}$ & $8.22 \pm 0.62^{+\#}$ \\
4 & $6.78 \pm 1.49$ & $8.23 \pm 0.79^{+\#}$ & $9.22 \pm 0.40^{+\#}$ \\
5 & $6.89 \pm 1.49$ & $10.40 \pm 0.70^{+\#}$ & $12.00 \pm 0.58^{+\#}$ \\
6 & $7.20 \pm 1.11$ & $10.53 \pm 0.24^{+\#}$ & $12.33 \pm 0.89^{+\#}$ \\
7 & $7.17 \pm 1.60$ & $11.90 \pm 0.26^{+\#}$ & $13.80 \pm 0.42^{+\#}$ \\
8 & $6.88 \pm 0.73$ & $11.96 \pm 0.55^{+\#}$ & $15.67 \pm 0.33^{+\#}$ \\
9 & $6.56 \pm 1.09$ & $12.50 \pm 0.28^{+\#}$ & $17.43 \pm 0.29^{+\#}$ \\
10 & $6.78 \pm 0.90$ & $13.67 \pm 0.34^{+\#}$ & $18.83 \pm 0.17^{+\#}$ \\
11 & $6.67 \pm 1.20$ & $15.00 \pm 0.58^{+\#}$ & $18.67 \pm 0.60^{+\#}$ \\
\hline
\end{tabular}

${ }^{+} p<0.05$ in comparison to water at the same time interval. $* p<0.05$ in comparison to honey at the same time interval. ${ }^{*} p<0.05$ in comparison to day 1 in each group 
by honey administration throughout the study period as compared to the water. Furosemide caused early and higher diuresis than honey. Furosemide caused a significant increase in the urine output in all the intervals, and it was more potent than honey.

A significant increase in the urinary volume was observed in all time intervals after the administration of honey or furosemide (Table-2). Furosemide was more potent than honey on days 7-11.

Honey caused a significant increase in the urine concentration of sodium and chloride, while the concentration of potassium did not change significantly (Figure-1). Furosemide caused a significant increase in the urine concentration of sodium, potassium, and chloride. The $\mathrm{Na}^{+} / \mathrm{K}^{+}$ratio for furosemide and honey was 0.90 and 0.95 , respectively, as compared to 0.69 for the control. Furosemide caused significantly higher sodium and potassium urinary excretion than honey.

Honey did not cause significant changes in the plasma electrolytes, creatinine, uric acid, and blood urea nitrogen level. However, it caused a significant increase in the creatinine clearance during all the time intervals (Table-3 and Figure-2). Furosemide caused a significant decrease in the plasma potassium and chloride level in comparison with the water group. It also increased creatinine clearance in all time intervals, and in comparison to honey, it was less potent on day 11.

Honey did not cause a significant change in the plasma osmolarity. However, it caused significant increase in the urine osmolarity, osmolar clearance, and free water clearance compared to the control (Table-4). Furosemide increased free water clearance and osmolar clearance and decreased urine osmolarity.

\section{Effect of honey on wound healing}

There was no significant difference in the diameter of the wounds treated with honey on day 1 and 3 as compared to the control (Figure-3). However, on days $7-12$, the wounds treated with honey or Madecassol showed significantly smaller size than wounds treated with the control $(\mathrm{p}<0.05)$. On day 12 , the size of wounds treated with honey was less than sized of wounds treated with Madecassol, but the difference was statistically insignificant. Figure-4 demonstrated the macroscopical changes occurred during the treatment with interventions.

\section{Discussion}

The physicochemical analysis of the honey revealed that the $\mathrm{pH}$ value and the free acidity value

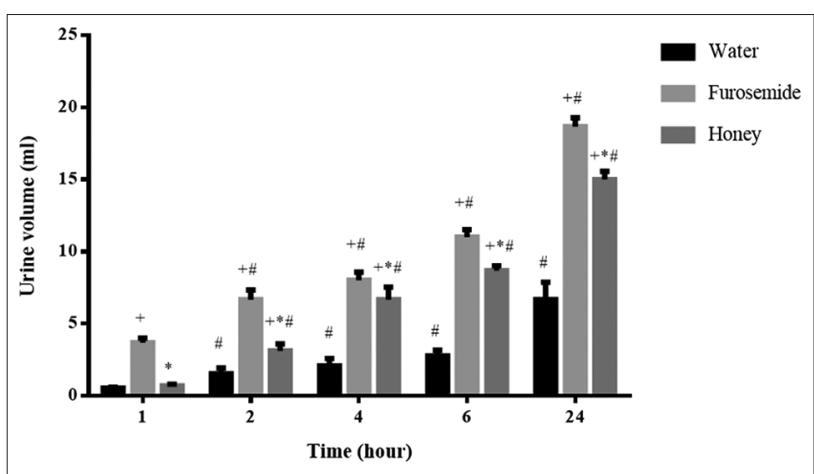

Figure-1: Urine volume $(\mathrm{ml})$ after a single oral dose of each intervention. ${ }^{+} p<0.05$ in comparison to water in each time interval. $* p<0.05$ in comparison to furosemide in each time interval. ${ }^{*} \mathrm{p}<0.05$ in comparison to urine volume at $1^{\text {st }} \mathrm{h}$ with the use of the same intervention.

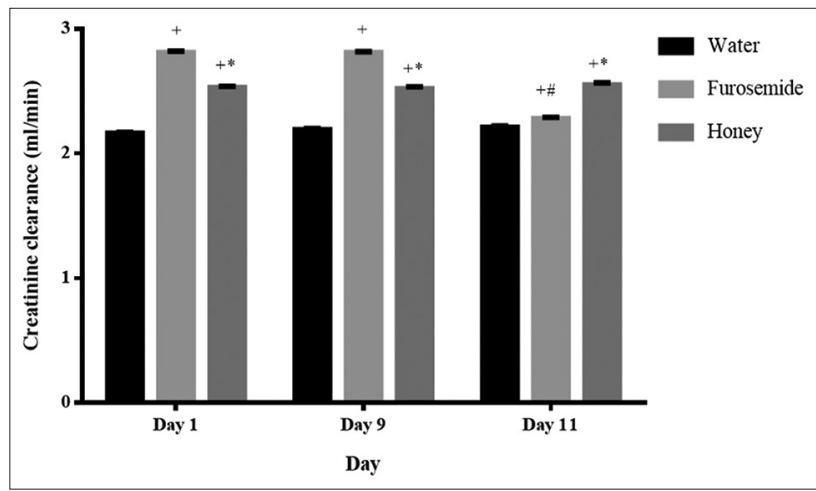

Figure-2: Effect of daily oral administration of honey or furosemide on creatinine clearance. ${ }^{+} p<0.05$ in comparison to water at the same time interval. $* p<0.05$ in comparison to furosemide at the same time interval. ${ }^{*} p<0.05$ in comparison to day 1 in each group.

Table-2: Effect of oral administration of honey and furosemide on urine volume and electrolyte excretion on day 11.

\begin{tabular}{|c|c|c|c|c|c|c|c|c|c|c|}
\hline \multirow[t]{2}{*}{ Interventions } & \multirow[t]{2}{*}{$\begin{array}{l}\text { Urine volume } \\
(\mathrm{ml} / 24 \mathrm{~h})\end{array}$} & \multicolumn{3}{|c|}{ Urine electrolytes } & \multicolumn{3}{|c|}{$\begin{array}{c}\text { Saluretic } \\
\text { index }\end{array}$} & \multirow[t]{2}{*}{$\begin{array}{l}\text { Diuretic } \\
\text { index }\end{array}$} & \multirow[t]{2}{*}{$\begin{array}{l}\text { Lipschtiz } \\
\text { value }\end{array}$} & \multirow[t]{2}{*}{ Ratio $\mathrm{Na}^{+} / \mathrm{K}^{+}$} \\
\hline & & $\mathrm{Na}^{+}$ & $\mathbf{K}^{+}$ & $\mathrm{Cl}^{-}$ & $\mathrm{Na}^{+}$ & $\mathbf{K}^{+}$ & $\mathrm{Cl}^{-}$ & & & \\
\hline Wrater & $6.6 \pm 1.20$ & $169 \pm 0.5$ & $243 \pm 0.64$ & $242 \pm 0.57$ & 1 & 1 & 1 & 1 & - & 0.69 \\
\hline Furosemide & $15.00 \pm 0.58^{+}$ & $278 \pm 3.7^{+}$ & $308 \pm 3.0^{+}$ & $281 \pm 1.1^{+}$ & 1.65 & 1.26 & 1.16 & 2.8 & - & 0.90 \\
\hline Honey & $18.6 \pm 0.6^{+}$ & $233 \pm 3.7^{+*}$ & $245 \pm 3.2 *$ & $298 \pm 1.5^{+*}$ & 1.38 & 1.00 & 1.23 & 2.25 & 0.80 & 0.95 \\
\hline
\end{tabular}

${ }^{+} \mathrm{p}<0.05$ in comparison to water. ${ }^{*} \mathrm{p}<0.05$ in comparison to furosemide

Table-3: Effect of honey and furosemide on plasma electrolytes and kidney function test on day 11.

\begin{tabular}{lcccccc}
\hline Interventions & Creatinine $\mathbf{( m g / d l})$ & Uric acid $\mathbf{( m g / d l )}$ & Urea $\mathbf{( m g / d l )}$ & $\mathbf{N a}^{+} \mathbf{m m o l} / \mathbf{I}$ & $\mathbf{K}^{+} \mathbf{m m o l} / \mathbf{I}$ & $\mathbf{C l}^{-} \mathbf{~ m m o l} / \mathbf{I}$ \\
\hline Water & $0.4 \pm 0.05$ & $11.2 \pm 0.08$ & $18 \pm 3$ & $163 \pm 1.2$ & $4.5 \pm 0.01$ & $100 \pm 1$ \\
Furosemide & $0.38 \pm 0.02$ & $11.5 \pm 1.3$ & $15 \pm 1$ & $160 \pm 2.3$ & $3.8 \pm 0.07^{+}$ & $85 \pm 7.7^{+}$ \\
Honey & $0.41 \pm 0.04$ & $12 \pm 1.5$ & $15 \pm 1$ & $161 \pm 14$ & $4.4 \pm 0.12$ & $90 \pm 5.1^{+}$ \\
\hline
\end{tabular}

${ }^{+} \mathrm{p}<0.05$ in comparison to water. ${ }^{*} \mathrm{p}<0.05$ in comparison to furosemide 
Table-4: Effect of daily administration of honey and furosemide on plasma osmolarity; urine osmolarity; osmolar clearance and clearance of free water on day 11.

\begin{tabular}{lccc}
\hline Variables & Water & Honey & Furosemide \\
\hline Urinary flow $(\mu \mathrm{l} / \mathrm{min})$ & $4.6 \pm 2.00$ & $10.4 \pm 2.80^{+}$ & $12.9 \pm 3.10^{+*}$ \\
$\mathrm{U}_{\text {osm }}\left(\mathrm{mOsm} / \mathrm{kgH}_{2} \mathrm{O}\right)$ & $825.8 \pm 12.1$ & $957.2 \pm 3.89^{+}$ & $1172 \pm 13.34^{+*}$ \\
$\mathrm{P}_{\text {osm }}\left(\mathrm{mOsm} / \mathrm{kgH}_{2} \mathrm{O}\right)$ & $324.6 \pm 7.5$ & $322.6 \pm 6.9$ & $321.3 \pm 8.8$ \\
$\mathrm{C}_{\mathrm{osm}}(\mu \mathrm{l} / \mathrm{min})$ & $11.7 \pm 2.67$ & $30.9 \pm 3.50^{+}$ & $47.27 \pm 2.20^{+*}$ \\
$\mathrm{C}_{\mathrm{H} 2 \mathrm{O}}(\mu \mathrm{l} / \mathrm{min})$ & $-10.2 \pm 1.30$ & $-29.5 \pm 2.34^{+}$ & $-49.4 \pm 4.29^{+*}$ \\
$\mathrm{~T}_{\mathrm{cH} \mathrm{O}}(\mu \mathrm{l} / \mathrm{min})$ & $10.2 \pm 2.20$ & $29.5 \pm 3.90^{+}$ & $49.4 \pm 2.80^{+*}$ \\
\hline
\end{tabular}

$+p<0.05$ in comparison to water. $* p<0.05$ in comparison to honey

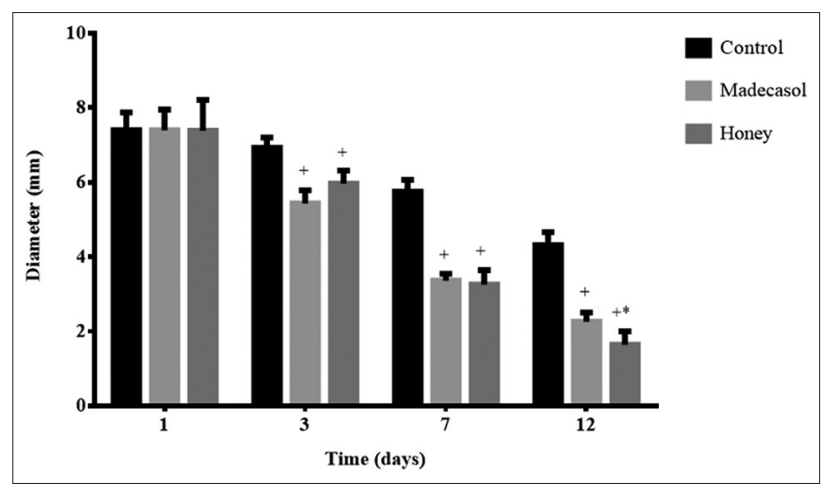

Figure-3: Diameter $(\mathrm{mm})$ of the wounds observed at each time interval following treatment by honey or Madecasol and compared with the control (no treatment). ${ }^{+} p<0.05$ in comparison to the control. $* p<0.05$ in comparison to Madecasol.

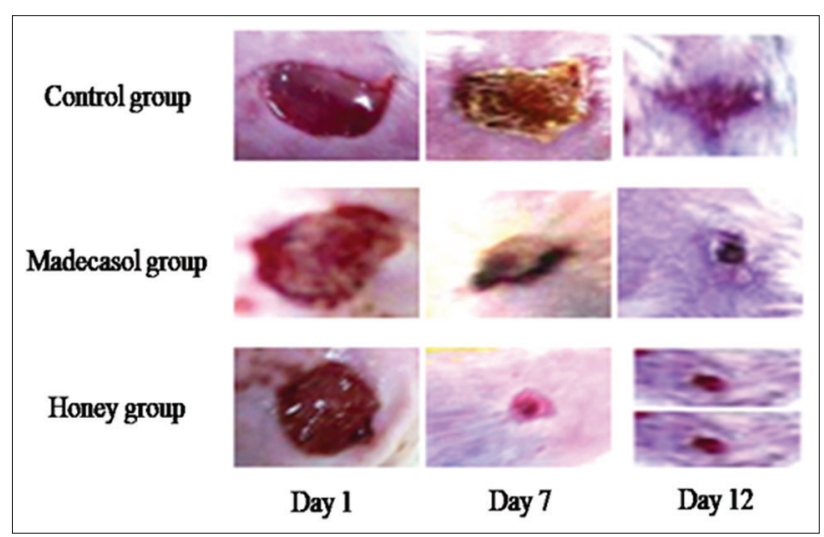

Figure-4: Macroscopic changes during wound healing with the use of various interventions.

were within the limits of European legislation and indicated the absence of undesirable fermentation $[33,34]$. The $\mathrm{pH}$ is acidic, and it is similar to honey $\mathrm{pH}$ found in other studies [35-38]. The determined acidity of honey is due to the presence of organic acids and inorganic ions.

The value of free acidity and lactone acidity is within the range of values of Moroccan honey samples that showed the values of free acidity, lactone acidity, and total acidity ranged from 11.0 to $42.5,4.0$ to 16.50 , and 17.50 to 59.0 , respectively [38]. The total acidity is the sum of free acidity and lactonic acidity. It was similar to the multifloral Portuguese honey acidity and relatively higher than multifloral honey acidity from Morocco carob honey $(49.89 \pm 1.24$ vs. $33.18 \mathrm{mEq} / \mathrm{kg}$ ) [25,27].
Moisture percentage of the Tulkarm honey is below the average limit of $\leq 20 \%$ for blossom honey [35]. The moisture value of Palestinian honey is in accordance with values recommended by the IHC, in 2009, and the Codex Standard for Honey 2001 and was similarly compared with the values obtained for carob honey from Italy and Portugal and Morocco [27,36,38].

The percentage of ash in the honey was within the limits of Codex Alimentarius. The percentage of ash value depends on the mineral contents. Honey collected in Italy and Turkey showed almost similar ash content $[36,39]$. The ash content in various honey samples collected in Morocco ranged between $0.13 \%$ and $0.69 \%$, and the largest value was detected in carob honey from Taounate Region $(0.69 \pm 0.01 \%)$ [38].

The electrical conductivity is a useful parameter to determine the botanical origin of honey and the difference between nectar and honeydew [33]. The electrical conductivity depends on the mineral content of the honey. The value found in the honey sample was higher than the maximum limits defined by the Codex Alimentarius Commission [40]. It was found that the electrical conductivity of honey samples from Morocco

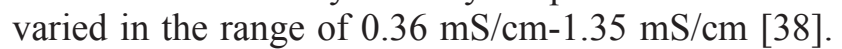
High values were found in carob honey from Taounate Region $(1.35 \pm 0.03 \mathrm{mS} / \mathrm{cm})$.

Phenolics compounds are important bioactive molecules found in honey. The total phenol and flavonoid (flavones and flavonols) contents of eight different Morrocan honey samples varied from 755.2 to $2452.2 \mathrm{mg} \mathrm{GAE} / \mathrm{kg}$ and 22.6 to $47.9 \mathrm{mg} \mathrm{QE} / \mathrm{kg}$, respectively [38]. Therefore, the flavones and flavonols found in Tulkarm honey were higher than the range of eight Moroccan honeys while polyphenols were within the range of the Moroccan honeys. Furthermore, the phenolic content of Tulkarm honey samples was higher than that reported in honey from Yemen (751.3-2462.1 mg/kg), Brazil (611.6$1113.7 \mathrm{mg}$ GAE$/ \mathrm{kg}$ ), India (490-980 mg GAE/kg), Serbia (274.4-614.2 mg GAE/kg), and Algeria (158.4$616.3 \mathrm{mg} / \mathrm{kg}$ ) [41-44].

The $\mathrm{IC}_{50}$ value of $\mathrm{ABTS}^{*+}$ was $3.16 \pm 0.70 \mathrm{mg} / \mathrm{ml}$; this value is within four multifloral Moroccan honeys and less than two Portugal multifloral honeys [25,27]. The $\mathrm{IC}_{50}$ value of DPPH was $17.14 \pm 1.40 \mathrm{mg} / \mathrm{ml}$ which is higher than Polish multiforal honeys and less than Slovenian honey $[30,45]$. 
It was found that the total antioxidant power of carob honey varied from $35.03 \mathrm{mg} \mathrm{AAE} / \mathrm{g}$ to $60.94 \mathrm{mg}$ $\mathrm{AAE} / \mathrm{g}$, which is less than that of Tulkarm honey [38]. The concentration of Tulkarm honey required to inhibit $50 \%$ of DPPH was higher than the concentration of carob honey $(12.54 \mathrm{mg} / \mathrm{ml}$ and $23.10 \mathrm{mg} / \mathrm{ml})$, Serbian honey $(11.16-48.48 \mathrm{mg} / \mathrm{ml})$, and Turkish honey $(12.56-152.40 \mathrm{mg} / \mathrm{ml})[38,41,46]$. The reducing power of Tulkarm honey was lower than reducing the power of carob honey $(1.87 \mathrm{mg} / \mathrm{ml}-4.40 \mathrm{mg} / \mathrm{ml})$ [38].

Furosemide increases urinary output and urinary excretion of sodium, potassium, and chloride by inhibiting $\mathrm{Na}^{+} / \mathrm{K}^{+} / 2 \mathrm{Cl}^{-}$symporter (cotransporter system) in the thick ascending limb of the Loop of Henley [47]. The study reveals that honey demonstrates a significant diuretic activity. Honey causes a significant increase in urine concentration of sodium and chloride, while the concentration of potassium did not change significantly. However, furosemide causes a significant increase in the urine concentration of sodium, potassium, and chloride as well as hypokalemia. Therefore, the action of honey is almost similar to thiazide diuretics, which increase the excretion of sodium and chloride by inhibition of $\mathrm{Na}^{+} / \mathrm{Cl}^{-}$symporter (cotransporter system) in the distal convoluted tubule [47]. Interestingly, contrary to thiazide and furosemide, honey did not cause hypokalemia that is a common side effect of loop or thiazide diuretics. This might be due to high levels of potassium presents in honey $[5,38]$. It was found that honey increases urine excretion of nitric oxide, and consequently, it was proposed that the diuretic effect of honey, partly, is due to increased urinary nitric oxide concentration [7]. Honey collected from Palestine shares the same diuretic activity with honey samples collected from Morocco and United Arab Emirates $[7,8]$.

Several studies showed that flavonoids have been linked to the diuretic effects $[48,49]$. This might explain, in part, the diuretic activity of honey. The glucose and fructose in honey might cause diuresis. However, we found that artificial honey causes insignificant changes in the urine volume in healthy individuals [7].

Regarding the wound healing potential of the Palestinian honey, the macroscopic examination of the wound reveals a significant decrease in the diameter of the wounds treated by honey as compared with wounds treated with Madecassol. The healing property of honey is mainly due to its anti-inflammatory, antioxidant, and antibacterial activity [50,51]. Furthermore, its acidity and hyperosmolarity, as well as the bioactive molecule such as flavonoids, hydrogen peroxide, glucose oxidase, gluconic acid, and MGO, play a major role in its activity $[50,52,53]$. The wound healing activity could also be due to inhibition of PG, stimulation of nitric oxide and modulating the release of anti-inflammatory cytokines and growth factors by monocytes [54,55]. Madecassol was used to compare its effect with honey. It is

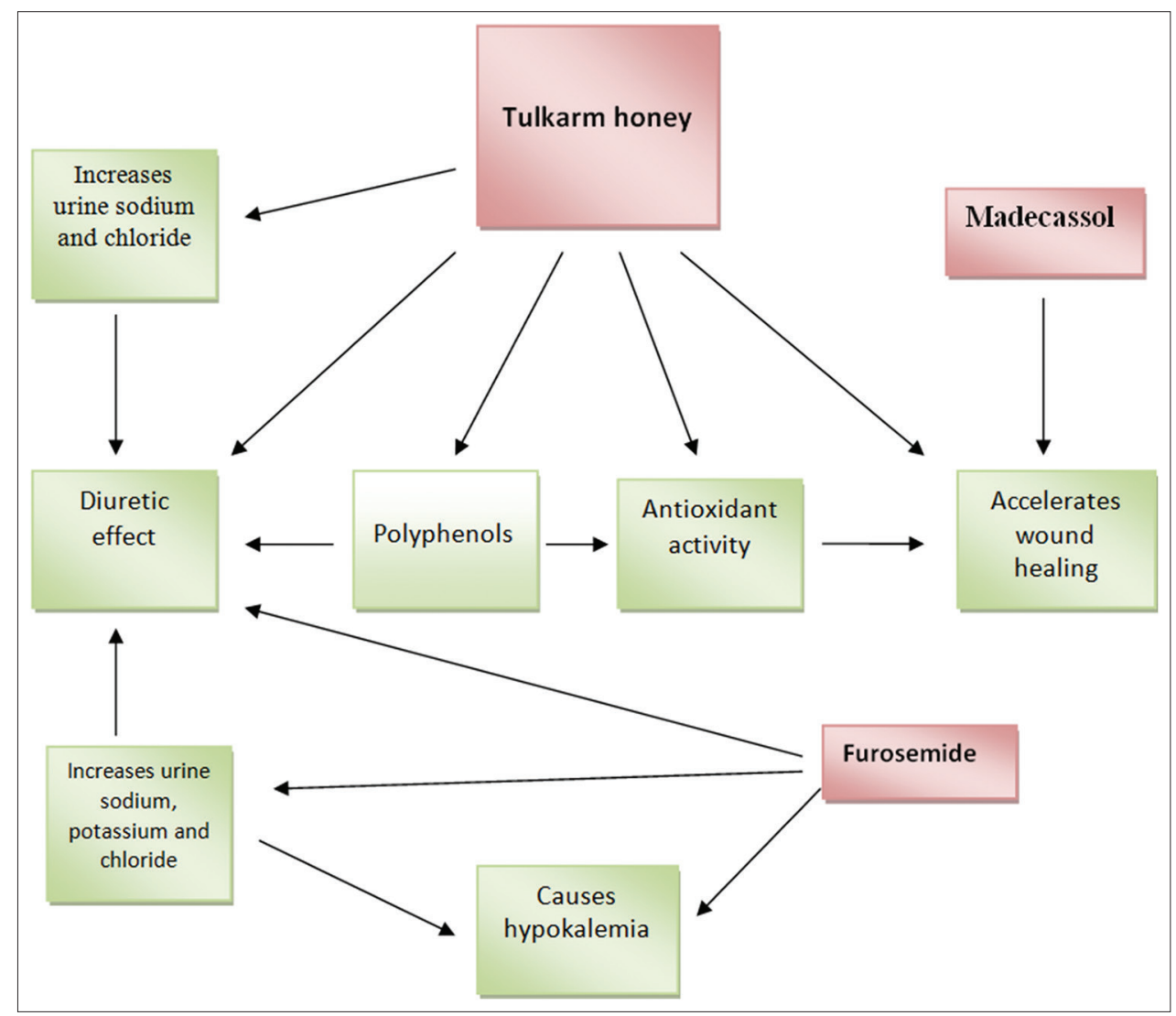

Figure-5: The effect of Tulkarm honey on wound healing and diuresis. 
commonly used products for burn, skin wrinkles, and wound management [56,57]. Their most beneficial effect appears to be the stimulation of maturation of scar by the production of Type I collagen and resulting decrease in the inflammatory reaction and myofibroblast production.

\section{Conclusion}

The findings showed, the physicochemical characterization, antioxidant and wound healing property, and diuretic effect of honey collected from Tulkarm, Palestine (Figure-5). Tulkarm honey contains phenols, flavonols, and flavones, and it exhibits considerable antioxidant activity. It also has a diuretic effect without affecting serum electrolytes or kidney function test. As compared to Madecassol, Tulkarm honey showed significant wound healing properties, which might be due to its antioxidant activity, acidity, nutritional content, or other factors such as anti-inflammatory and antimicrobial activity.

\section{Authors' Contributions}

$\mathrm{HI}, \mathrm{MB}$, and $\mathrm{BL}$ involved in the design and conception of the experimental protocols and participated in the experimental work; NA and WA wrote the paper and prepared for publication, conducted the statistical analysis of the work, and did acquisition and interpretation of the data. All authors read and approved the final manuscript.

\section{Acknowledgments}

The authors would like to thank Laboratory of Physiology, Pharmacology and Environmental Health, Faculty of Sciences, Dhar El Mehraz, for providing the facilities to carry out the research work, and to New York Medical Care for Nephrology, (N Al-Waili MD, PhD), NY, USA, for paying the publication fee. The study was funded by the University Sidi Mohamed Ben Abdallah, P.O. Box 1796. Fez. Atlas. Fez. Morocco, (USMBA/PPSE/L08FSDM2016).

\section{Competing Interests} interests.

The authors declare that they have no competing

\section{References}

1. Iqbal, M., Anjum, A., Ali, M., Hussain, F., Ali, S., Muhammad, A., Irfan, M., Ahmad, A., Irfan, M. and Shabbir, A. (2015) Assessment of microbial load of unpasteurized fruit juices and in vitro antibacterial potential of honey against bacterial isolates. Open Microbiol. J., 9(2): 26-32.

2. Yaghoobi, R., Kazerouni, A. and Kazerouni, O. (2013) Evidence for clinical use of honey in wound healing as an anti-bacterial, anti-inflammatory, anti-oxidant and anti-viral agent: A review. Jundishapur. J. Nat. Pharm. Prod., 8(2): 100-104.

3. Aazza, S., Lyoussi, B., Antunes, D. and Miguel, M. (2013) Physicochemical characterization and antioxidant activity of 31 Moroccan honeys. J. Food Biochem., 13(1): 1-32.

4. Al-Waili, N.S., Al-Waili, F.S., Akmal, M., Ali, A.,
Salom, K.Y. and Al Ghamdi, A.A. (2014) Effects of natural honey on polymicrobial culture of various human pathogens. Arch. Med. Sci., 12(3): 246-250.

5. AL-Waili, N., Al Ghamdi, A., Ansari, M.J., Al-Attal, Y., Al-Mubarak, A. and Salom, K. (2013) Differences in composition of honey samples and their impact on the antimicrobial activities against drug multiresistant bacteria and pathogenic fungi. Arch. Med. Res., 44(4): 307-316.

6. Al-Waili, N.S. (2004) Natural honey lowers plasma glucose, C-reactive protein, homocysteine, and blood lipids in healthy, diabetic, and hyperlipidemic subjects: Comparison with dextrose and sucrose. J. Med. Food, 7(1): 100-107.

7. Al-Waili, N. (2005) Effects of honey on the urinary total nitrite and prostaglandins concentration. Int. Urol. Nephrol., 37(1): 107-111.

8. El-Haskoury, R., Zizi, S., Touzani, S., Al-Waili, N., Al-Ghamdi, A. and Lyoussi, L. (2015) Diuretic activity of carob honey (Ceratonia siliqua L); Comparison with furosemide. Afr. J. Tradit. Complement. Altern. Med., 12(2): 128-133.

9. Fihri, A., Al-Waili, N.S., El-Haskoury, R., Bakour, M., Amarti, A., Ansari, M.J. and Lyoussi, B. (2016) Protective effect of morocco carob honey against lead-induced anemia and hepato-renal toxicity. Cell. Physiol. Biochem., 39(1): 115-122.

10. Al-Waili, N.S., Saloom, K.Y., Akmal, M., Al-Waili, F., Al-Waili, T.N., Al-Waili, A.N. and Ali, A. (2006) Honey ameliorates influence of hemorrhage and food restriction on renal and hepatic functions, and hematological and biochemical variables. Int. J. Food. Sci. Nutr., 57(4): 353-362.

11. Al-Waili, N.S., Saloom, K.Y., Al-Waili, T.N., Al-Waili, A.N., Akmal, M., Al-Waili, F.S. and Al-Waili, H.N. (2006) Influence of various diet regimens on deterioration of hepatic function and hematological parameters following carbon tetrachloride: A potential protective role of natural honey. Nat. Prod. Res., 20(12): 1258-1264.

12. Al-Waili, N.S. (2003) Intravenous and intrapulmonary administration of honey solution to healthy sheep: Effects on blood sugar, renal and liver function tests, bone marrow function, lipid profile, and carbon tetrachloride-induced liver injury. J. Med. Food, 6(2): 231-247.

13. Al-Waili, N.S., Saloom, K.Y., Akmal, M., Al-Waili, F., Al-Waili, T.N., Al-Waili, A.N. and Ali, A. (2006) Honey ameliorates influence of hemorrhage and food restriction on renal and hepatic functions, and hematological and biochemical variables. Int. J. Food Sci. Nutr., 57(5-6): 353-362.

14. El Denshary, E.S., Al-Gahazali, M.A., Mannaa, F.A., Salem, H.A., Hassan, N.S. and Abdel-Wahhab, M.A. (2012) Dietary honey and ginseng protect against carbon tetrachloride-induced hepatonephrotoxicity in rats. Exp. Toxicol. Pathol., 64(7): 753-760.

15. Hamad, R., Jayakumar, C., Ranganathan, P., Mohamed, R., El-Hamamy, M.M., Dessouki, A.A., Ibrahim, A. and Ramesh, G. (2015) Honey feeding protects kidney against cisplatin nephrotoxicity through suppression of inflammation. Clin. Exp. Pharm. Physiol., 42(8): 843-848.

16. Zoheir, K.M., Harisa, G.I., Abo-Salem, O.M. and Ahmad, S.F. (2015) Honeybee is a potential antioxidant against cyclophosphamide-induced genotoxicity in albino male mice. Pak. J. Pharm. Sci., 28(3): 973-981.

17. Al-Yahya, M., Mothana, R., Al-Said, M., Al-Dosari, M., Al-Musayeib, N., Al-Sohaibani, M., Parvez, M.K. and Rafatullah, S. (2013) Attenuation of ccl4-induced oxidative stress and hepatonephrotoxicity by Saudi Sidr honey in RATS. Evid. Based Complement Altern. Med., 2013: 569037.

18. Al-Seeni, M.N., El Rabey, H.A. and Al-Solamy, S.M. (2015) The protective role of bee honey against the toxic effect of melamine in the male rat kidney. Toxicol. Ind. Health, 31(6): 485-493.

19. Erejuwa, O.O., Gurtu, S., Sulaiman, S.A., Ab Wahab, M.S., 
Sirajudeen, K.N. and Salleh, M.S. (2010) Hypoglycemic and antioxidant effects of honey supplementation in streptozotocin-induced diabetic rats. Int. J. Vitam. Nutr. Res., 80(1): 74-82.

20. Sawalha, A.F. (2007) Complementary and alternative medicine (CAM) in Palestine: Use and safety implications. $J$. Altern. Complement Med., 13(2): 263-269.

21. Abdul-Ghani, A.S., Dabdoub, N., Muhammad, R., AbdulGhani, R. and Qazzaz, M. (2008) Effect of Palestinian honey on spermatogenesis in rats. J. Med. Food, 11(4): 799-802.

22. Odeha, I., Abu-Lafia, S., Dewika, H., Al-Najjara, I., Imamb, A., Dembitskyc, V. and Hanušc, L.A. (2007) Variety of volatile compounds as markers in Palestinian honey from Thymus capitatus, Thymelaea hirsuta, and Tolpis virgate. Food Chem., 101(11): 1393-1397.

23. Odeh, I., Abu-Lafi, S. and Al-Najjar, I. (2013) Determination of potential volatiles markers from citrus, eucalyptus, cotton and wildflower Palestinian honeys using SPME followed by GCMS analysis. Int. Food Res. J., 20(11): 1243-1247.

24. Bogdanov, S. (2002) Harmonized Methods of the International Honey Commission. Swiss Bee Research Centre, FAM, Liebefeld.: http://www.ihc-platform.net/ihcmethods2009.pdf.

25. Borrell, R., Visconti, A., Mennella, C., Anese, M. and Fogliano, V. (2002) Chemical characterization and antioxidant properties of coffee melanoidins. J. Agric. Food Chem., 50(12): 6527-6533.

26. Gorjanovic, S., Alvarez-Suarez, J., Novakovic, M., Pastor, F., Pezo, L., Battino, M. and Sužnjevic D. (2013) Comparative analysis of antioxidant activity of honey of different floral sources using recently developed polarographic and various spectrophotometric assays. J. Food Comp. Anal., 30(1): 13-18.

27. Aazza, S., Lyoussi, B., Antune, D. and Miguel, M. (2013) Physicochemical characterization and antioxidant activity of commercial Portuguese honeys. J. Food Sci., 78(12): 1159-1165.

28. Miguel, M., Doughmi, O., Aazza, S., Antunes, D. and Lyoussi, B. (2014) Antioxidant, anti-inflammatory and acetylcholinesterase inhibitory activities of propolis from different regions of Morocco. Food Sci. Biotechnol., 23(1): 313-322.

29. Sarmento, S., Pereira, D.S., Adriana, E., Sarmento, D., Sarmento, D. and Santos, D. (2013) Phenolic compounds, melissopalynological, physicochemical analysis and antioxidant activity of jandarra (Melipona subnitida) honey. $J$. Food Comp. Anal., 29(1): 10-18.

30. Padmanabhan, P. and Jangle, S.N. (2012) Evaluation of DPPH radical scavenging activity and reducing power of four selected medicinal plants and their combinations. Int. J. Pharm. Sci. Drug Res., 4(2): 143-146.

31. Marghitas, A., Stanciu, G., Dezmirean, S., Bobis, B., Olimpia, P., Stefan, B. and Graca, C. (2009) In vitro antioxidant capacity of honeybee-collected pollen of selected floral origin harvested from Romania. Food Chem., 115(9): 878-883.

32. Prieto, P., Pineda, M. and Aguilar, M. (1999) Spectrophotometric quantitation of antioxidant capacity through the formulation of a phosphomolybdenum complex: Specific application of Vitamin E. Anal. Biochem., 269(3): 337-341.

33. Bogdanov, S., Ruoff, K. and Oddo, L.P. (2004) Physicochemical methods for the characterisation of unifloral honeys: A review. Apidologie, 35(1): S4-S17.

34. EU Council. (2002) Council directive 2001/11 O/EC of 20 December 2001 relating to honey. Off. J. Eur. Commun., L 10(1): 47-52.

35. Aazza, S., Lyoussi, B., Antune, D. and Miguel, M. (2014) Physicochemical characterization and antioxidant activity of 17 commercial Moroccan honeys. Int. J. Food Sci. Nutr., 65(4): 449-457.
36. Ferrauto, G. and Pavone, P. (2013) Palynological, physicochemical and organoleptic characteristics of carob tree (Ceratonia siliqua L.) honey from Sicily. Int. J. Food Sci. Tech., 48(12): 1596-1602.

37. Gomes, S., Dias, L., Moreira, L., Rodrigues, P. and Estevinho, L. (2010) Physicochemical, microbiological, and antimicrobial properties of commercial honeys from Portugal. Food Chem. Toxicol., 48(4): 544-548.

38. El-Haskoury, R., Kriaa, W., Lyoussi, B. and Makni, M. (2018) Ceratonia siliqua honeys from Morocco: Physicochemical properties, mineral contents, and antioxidant activities. J. Food Drug Anal., 26(1): 67-73.

39. Yücel, Y. and Sultanog, P. (2013) Characterization of honeys from Hatay region by their physicochemical properties combined with chemometrics. Food Biosci., 1(1): 16-25.

40. Codex Alimentarius Commission. (2001) Revised codex standard for honey, codex STAN 12-1981, Rev. 1 1987, Rev. 2 2001. Codex Stand., 12(1): 1-7.

41. Cetkovic, G., Saponjac, V., Stajcic, S., Vulic, J., Djilas, S., Stajner, D. and Popović, B. (2014) Evaluation of phenolic content, antioxidant activity and sensory characteristics of Serbian honey-based product. Ind. Crop. Prod., 62(1): 1-7.

42. Saxena, S., Gautam, S. and Sharma, A. (2010) Physical, biochemical, and antioxidant properties of some Indian honeys. Food Chem., 118(3): 391-397.

43. Mouhoubi-Tafinine, Z., Ouchemoukh, S. and Tamendjari, A. (2016) Antioxidant activity of some Algerian honey and propolis. Ind. Crop. Prod., 88(1): 85-90.

44. Al-Mamary, M., Al-Meeri, A. and Al-Habori, M. (2002) Antioxidant activities and total phenolics of different types of honeys. Nutr. Res., 22(12): 1041-1047.

45. El-Guendouz, S., Al-Waili, N., Aazza, S., Elamine, Y., Zizi, S., Al-Waili, T. and Lyoussi, B. (2017) Antioxidant and diuretic activity of co-administration of Capparis spinosa honey and propolis in comparison to furosemide. Asian Pac. J. Trop. Med., 10(11): 974-980.

46. Can, Z., Yildiz, O., Sahin, H., Turumtay, E.A., Silici, S. and Kolayli, S. (2015) An investigation of Turkish honeys: Their physicochemical properties, antioxidant capacities and phenolic profiles. Food Chem., 180(2): 133-141.

47. Jackson, E. (1996) Drugs affecting renal and cardiovascular function. In: Hardman, J.C., Gilman, A.G. and Limbird, L.E. (Eds.). Goodman and Gilman's the Pharmacological Basis of Therapeutics. $9^{\text {th }}$ ed. Pergamon Press, New York. p685-713.

48. Jouad, H., Lacaille-Dubois, M., Lyoussi, B. and Eddouks, M. (2001) Effects of the flavonoids extracted from Spergularia purpurea Pers. On arterial blood pressure and renal function in normal and hypertensive rats. J. Ethnopharmacol., 76(2): 159-163.

49. Wu, J. and Muir, A. (2008) Isoflavone content and its potential contribution to the antihypertensive activity in soybean angiotensin I converting enzyme inhibitory peptides. $J$. Agric. Food Chem., 56(12): 9899-9904.

50. Hadagali, M. and Chua, L. (2014) The anti-inflammatory and wound healing properties of honey. Eur. Food Res. Technol., 23(9): 1003-1014.

51. Vallianou, N., Gounari, P., Skourtis, A., Panagos, J. and Kazazis, C. (2014) Honey and its anti-inflammatory, anti-bacterial and anti-oxidant properties. Gen. Med. (Los Angel), 291(2): 1-5.

52. Bashkaran, K., Zunaina, E., Bakiah, S., Sulaiman, S., Sirajudeen, K. and Naik, V. (2011) Anti-inflammatory and antioxidant effects of Tualang honey in alkali injury on the eyes of rabbits: Experimental animal study. $B M C$ Complement Altern. Med., 11(1): 1-11.

53. Atrott, J. and Henle, T. (2009) Methylglyoxal in Manuka honey - Correlation with antibacterial properties. Czech. J. Food Sci., 27: S163-S165.

54. Tonks, A.J., Cooper, R.A., Jones, K.P., Blair, S., Parton, J. and Tonks, A. (2003) Honey stimulates inflammatory cytokine production from monocytes. Cytokine, 21(3): 242-247. 
55. Al-Waili, N. and Boni, N. (2003) Natural honey lowers plasma prostaglandin concentrations in normal individuals. J. Med. Food, 6(2): 129-133.

56. Shetty, B.S., Udupa, S.L. and Udupa,A.L. (2008) Biochemical analysis of granulation tissue in steroid and Centella asiatica
(Linn) treated rats. Pharm. Online, 2(6): 624-632.

57. Lee, J., Jung, E., Lee, H., Seo, Y., Koh, J. and Park, D. (2008) Evaluation of the effects of a preparation containing asiaticoside on periocular wrinkles of human volunteers. Int. J. Cosmet. Sci., 30(3): 167-173.

$* * * * * * * *$ 